\title{
Critical review of multidisciplinary approaches for managing sinonasal tumors with orbital involvement
}

\author{
Approcci multidisciplinari per la gestione dei tumori nasosinusali con invasione \\ orbitaria: revisione critica della letteratura
}

\begin{abstract}
Paolo Castelnuovo ${ }^{1,2}$, Alessia Lambertoni ${ }^{1}$, Giorgio Sileo ${ }^{1}$, Marco Valentini ${ }^{1}$, Apostolos Karligkiotis ${ }^{1}$, Paolo Battaglia1,2, Mario Turri-Zanoni ${ }^{1,2}$

${ }^{1}$ Division of Otorhinolaryngology, Department of Biotechnology and Life Sciences, University of Insubria, Varese, Italy; ${ }^{2}$ Head and Neck Surgery \& Forensic Dissection Research center (HNS\&FDRC), Department of Biotechnology and Life Sciences, University of Insubria, Varese, Italy
\end{abstract}

\begin{abstract}
SUMMARY
Orbital invasion is frequently observed in tumors involving the maxillary, ethmoid and frontal sinuses given the proximity of the orbit to the sinonasal tract and ventral skull base. The main objective of the present review is to determine the existing evidences on the frequency, treatment, and outcomes of orbital invasion in benign and malignant sinonasal tumors. A systematic review of the literature published from 1995 to 2020 was performed and data sources included PubMed, Cochrane library, NCBI Bookshelf, National Guideline Clearinghouse. Orbital invasion was reported in $2-4 \%$ of inverted papillomas, $12-15 \%$ of fibro-osseous lesions, $27-32 \%$ of juvenile angiofibromas, $35-45 \%$ of low-grade malignancies, and $50-80 \%$ of high-grade cancers. Surgical resection with negative margins represents the cornerstone of management for benign and low-grade malignant tumors. Histology-specific induction chemotherapy can be used for high-grade sinonasal cancers in order to downstage the tumor and increase the possibility of orbital preservation. When a significant response to induction chemotherapy is observed, exclusive chemoradiation should be offered to improve overall survival rates. Appropriate reconstruction of any surgical defects is essential in order to minimize complications and optimize functional and aesthetic outcomes. Orbital apex invasion represents a negative prognostic factor. In conclusion, a multidisciplinary teamwork is mandatory to maximize local control, minimize morbidity and improve orbital preservation rates.
\end{abstract}

KEY WORDS: anterior skull base, endoscopic endonasal surgery, induction chemotherapy, orbital exenteration; sinonasal tumors

\section{RIASSUNTO}

La vicinanza anatomica dell'orbita con il compartimento nasosinusale e la base cranica giustifica il fatto che un'invasione orbitaria possa essere frequentemente osservata nei tumori che originano dall'etmoide, dal seno mascellare e dal seno frontale. L'obiettivo principale di questa review è quello di analizzare le evidenze scientifiche a oggi disponibili in letteratura circa la frequenza, le strategie di trattamento e i risultati ottenuti nella gestione dei tumori nasosinusali benigni e maligni con invasione orbitaria. È stata condotta una revisione sistematica della letteratura scientifica pubblicata dal 1995 al 2020. Un'invasione dell'orbita è stata osservata nel 2-4\% dei papillomi invertiti, nel 12-15\% delle lesioni fibro-ossee, nel 27-32\% degli angiofibromi giovanili, nel 35-45\% dei tumori maligni ben differenziati, e nel 50-80\% delle neoplasie maligne scarsamente differenziate. L'asportazione chirurgica radicale con margini di resezione negativi rappresenta il caposaldo per il trattamento delle neoplasie benigne e maligne a basso grado. Schemi di chemioterapia di induzione specifici per ogni sottotipo istologico rappresentano invece il trattamento di scelta per i tumori maligni scarsamente differenziati, nel tentativo di ridurre il volume di malattia e aumentare le possibilità di preservazione del contenuto orbitario. Nei casi in cui si osservi una risposta significativa alla chemioterapia di induzione, un trattamento radio-chemioterapico esclusivo con intento radicale è in grado di migliorare $i$ risultati di sopravvivenza oncologica, lasciando alla chirurgia solo un ruolo di salvataggio in caso di
Received: November 8, 2020

Accepted: February 4, 2021

\section{Correspondence}

Mario Turri-Zanoni

Unit of Otorhinolaryngology, Department of Biotechnology and Life Sciences, University of Insubria, Ospedale di Circolo e Fondazione Macchi, via Guicciardini 9, 21100 Varese, Italy

E-mail: tzmario@inwind.it

\section{Funding}

None.

Conflict of interest

The Authors declare no conflict of interest.

How to cite this article: Castelnuovo P, Lambertoni A, Sileo G, et al. Critical review of multidisciplinary approaches for managing sinonasal tumors with orbital involvement. Acta Otorhinolaryngol Ital 2021;41(SUPPL.1):S76-S89. https://doi.org/10.14639/0392-100X-suppl.1-41-2021-08

(C) Società Italiana di Otorinolaringoiatria e Chirurgia Cervico-Facciale

\section{(c) (1) $(2)$}

This is an open access article distributed in accordance with the CC-BY-NC-ND (Creative Commons Attribution-NonCommercial-NoDerivatives 4.0 International) license. The article can be used by giving appropriate credit and mentioning the license, but only for non-commercial purposes and only in the original version. For further information: https:// creativecommons.org/licenses/by-nc-nd/4.0/deed.en 
persistenza o recidiva di malattia. In caso di preservazione dell'orbita, appropriate strategie di ricostruzione devono essere pianificate durante l'intervento chirurgico al fine di minimizzare possibili complicanze post-operatorie e per ottimizzare i risultati estetici e funzionali a lungo termine. L'infiltrazione dell'apice orbitario rappresenta il fattore prognostico negativo principale nel trattamento di queste neoplasie. Un lavoro di squadra all'interno di un gruppo multidisciplinare è indispensabile per ottimizzare il controllo locale di malattia, ridurre la morbilità per il paziente e aumentare le possibilità di preservazione dell'orbita.

PAROLE CHIAVE: base cranica anteriore, chirurgia endoscopica endonasale, chemioterapia di induzione, exenteration orbitae, tumori nasosinusali

\section{Introduction}

The proximity of the orbit to the sinonasal tract and ventral skull base facilitates tumoral infiltration of the orbital content via preformed pathways (e.g. inferior and superior orbital fissure, anterior and posterior ethmoidal foramina, nasolacrimal duct), neurovascular structures (e.g. infraorbital and supratrochlear nerves; ethmoidal arteries), or by direct extension through the bone (e.g. lamina papyracea, orbital floor and roof, nasal bones). The periorbit is a highly resistant barrier against invasion but, once the tumor has passed through it, no further barriers are able to prevent orbital content infiltration. Orbital involvement poses unique challenges in the management of sinonasal benign and malignant tumors since the eye represents a borderline anatomical region, between the intracranial and extracranial compartment, containing many neurovascular structures, with also relevant functional and aesthetic implications.

Traditionally, the standard treatment for sinonasal tumors in close proximity to the orbit was radical excision with orbital exenteration ${ }^{1}$. Over the past 20 years, the increased attention to patient's quality of life along with the development of endoscopic surgery and advances in multimodal treatment strategies have led to significant progresses in the management of sinonasal tumors with orbital invasion. As a result, in recent years, treatment protocols including orbital preservation have been increasingly adopted ${ }^{2,3}$.

However, there are still several open issues. The definition of "orbital invasion" represents a source of confusion since a universally accepted stratification of the degrees of orbital invasion is lacking. Moreover, data emerging from the case-series available in literature are difficult to compare and sometimes conflicting in terms of surgical and non-surgical treatments adopted, indications for orbital preservation, needs for orbital reconstruction and recurrence rates. In the present review, we analyze the multidisciplinary approaches currently available for managing benign and malignant sinonasal tumors invading the orbit, in an effort to critically appraise their survival, functional and aesthetic outcomes. The systematic review of the literature was conducted in accordance with current guidelines. Data sources including PubMed, Cochrane library, NCBI Bookshelf, National Guideline Clearinghouse were searched using keywords as follows: "sinonasal neoplasm"; "orbit"; "orbital involvement"; "sinonasal benign tumors"; "sinonasal malignant tumors"; "orbital management". Our research was focused on the time period ranging from January 1995 to June 2020, in order to avoid discrepancy and to promote data consistency. Among the 137 selected articles, only the studies that met the following criteria were included: 1) English language articles; 2) adequate number of patients for significant statistical analysis; 3 ) appropriate survival analysis to compare data; 4) accurate description of orbital invasion and concerning survival data. Following these inclusion criteria, 21 articles were selected to be reviewed.

\section{Diagnosis}

Symptoms can result from orbital compression, nasolacrimal duct obstruction, and real infiltration of the orbital content. Therefore, diplopia, epiphora, chemosis, visual changes, and proptosis may be observed in approximately $50 \%$ of the cases ${ }^{4}$. However, the absence of these findings does not rule out the occurrence of tumoral invasion of the orbit. Computerized tomography (CT) of the paranasal sinuses is paramount for identification of orbital bone erosion or reabsorption, and enlargement of fissures and foramina. Moreover, bony lesions such as fibro-osseous tumors can be easily detected using the CT scan. Magnetic resonance imaging (MRI) is superior for analyzing orbital soft tissues, and distinguishing inflammatory secretions (e.g. in the lacrimal sac) from tumor. In addition, by comparing T1-weighted contrast enhanced and T2-weighted sequences, periorbital and extraocular muscles invasion can be distinguished from other changes such as peritumoral edema. The MRI protocol may be further refined by adding dynamic contrastenhanced (DCE) and diffusion-weighted sequences (DWI) in order to better analyze the interface between orbit and tumor in difficult cases of recurrences after previous surgery and/or radiotherapy ${ }^{5}$. In the suspect of a vascular tumor (e.g. juvenile angiofibroma), an angio-MRI and/or an angiography should be also performed in order to study the distribution of the arterial feeders to the tumor and, possibly, embolize them. With the exception of fibro-osseous lesions and of vascular tumors, where the diagnosis is exclusively 
based on radiology, all other cases of sinonasal tumors need an endoscopic endonasal evaluation with multiple biopsies to define the tumoral histology and plan the most appropriate range of multimodal treatment. In case of malignancy, neck ultrasound and total body contrast-enhanced CT scan or positron emission tomography (PET) scan are obtained to rule out regional or systemic spread, respectively.

\section{Benign tumors}

Benign tumors of the paranasal sinuses are a heterogeneous group of diseases, that reflects the wide spectrum of different tissues present in the sinonasal cavities from which they could originate. Rare pathologies per se, they might involve the orbit in a small percentage of cases, ranging from 2 to $15 \%$; therefore, few data are available in literature (Tab. I). These tumors are generally slow growing lesions that compress without infiltrating the surrounding anatomical structures, invading the orbital compartment by means of bone reabsorption or via preformed skull fissures or foramina. In the majority of cases, the integrity of the periorbital layer is maintained, while the displacement of the orbital content can cause proptosis, diplopia due to extrinsic muscles abnormal mobility, decreased visual acuity until blindness secondary to optic nerve compression, ocular pain and epiphora ${ }^{6}$.

The standard treatment of benign tumors is surgical resection, using endoscopic endonasal techniques, transfacial/ transcranial resection, transorbital surgery or combined approaches, which could overcome the limits of a single surgical technique in the management of lesions affecting such a complex anatomical compartment. Orbital exenteration is rarely required for benign tumors and orbital preservation is generally obtained. Globally, when selecting the surgical approach, it is necessary to carefully balance the complete excision with the associated surgical morbidity, taking also into account that some selected residual benign tumors, usually tend to remain stable over time.

\section{Fibro-osseous lesions (FOLs)}

Benign sinonasal fibro-osseous tumors involving the orbit commonly arise from the frontal and ethmoidal bones, with osteomas representing the most frequent subtypes ${ }^{6}$. While osteomas generally originate or involve the orbital bony walls, without invasion of the orbital contents, other FOLs such as fibrous dysplasia and ossifying fibroma may present higher rates of intraorbital invasion and related clinic ${ }^{7}$. A common feature in this group of lesions is the slow rate of growth, which often makes patients asymptomatic for a long period of time; for this reason, the "wait and scan" policy could be a valid option while the choice of surgical resection should be based on the site of the tumor, its growth pattern as well as on the clinical presentation ${ }^{8-10}$. The endoscopic endonasal technique has been proposed by many authors as a minimally invasive and effective surgical approach to treat these tumors, by using the drill cavitation technique. In this regard, the intraorbital component of the lesion can be used as a corridor to pass through

Table I. Literature review of the main case-series describing treatment outcomes of sinonasal benign tumors with orbital involvement.

\begin{tabular}{|c|c|c|c|c|c|c|}
\hline Author, year & N. of cases & Histology & $\begin{array}{l}\text { Endoscopic or external } \\
\text { surgical approach \& other } \\
\text { treatments }\end{array}$ & $\begin{array}{l}\text { Mean } \\
\text { follow-up } \\
\text { (months) }\end{array}$ & $\begin{array}{c}\text { Recurrences \& } \\
\text { persistences/treated } \\
\text { cases }\end{array}$ & $\begin{array}{c}\text { Orbital } \\
\text { preservation rate }\end{array}$ \\
\hline Wang, $2014^{9}$ & 14 & Ossifying fibroma & $\begin{array}{c}\text { 10, EEA }(71 \%) \\
4, \text { TTA }(29 \%)\end{array}$ & 25 & $6 / 14(43 \%)$ & $14 / 14(100 \%)$ \\
\hline Ye, $2017^{11}$ & 12 & Ossifying fibroma & 12, EEA (100\%) & 43.1 & $2 / 12(17 \%)$ & $12 / 12(100 \%)$ \\
\hline $\begin{array}{l}\text { Turri-Zanoni, } \\
2012^{12}\end{array}$ & 6 & Osteoma & $\begin{array}{c}\text { 4, EEA }(66 \%) \\
\text { 1, EEA+TTA (17\%) } \\
\text { 1, TTA }(17 \%)\end{array}$ & 72.6 & - & $6 / 6(100 \%)$ \\
\hline Bertin, 202048 & 12 & Fibrous dysplasia & $\begin{array}{c}\text { 6, TTA }(50 \%) \\
\text { 3, Bifosfonate }(25 \%) \\
\text { 3, Wait\&scan }(25 \%)\end{array}$ & 20.8 & $12 / 12(100 \%)$ & $12 / 12(100 \%)$ \\
\hline Ricalde, $2001^{10}$ & 6 & Fibrous dysplasia & 6, TTA (100\%) & NA & NA & 6/6 (100\%) \\
\hline Elmer, $1995^{15}$ & 10 & Inverted papilloma & $\begin{array}{c}2, \operatorname{TTA}(20 \%) \\
8 \text {, Orbital exenteration }\end{array}$ & 51.6 & $8 / 10(80 \%)$ & $2 / 10(20 \%)$ \\
\hline Saldana, $2013^{18}$ & 6 & Inverted papilloma & $\begin{aligned} 6, & \text { TTA }(100 \%) \\
+ & +(3, \mathrm{RT})\end{aligned}$ & 22.8 & - & $5 / 6(84 \%)$ \\
\hline $\mathrm{Xu}, 2012^{23}$ & 18 & Juvenile angiofibroma & $\begin{array}{c}\text { 10, EEA + TTA } \\
\text { 8, TTA } \\
+(4, \mathrm{RT})\end{array}$ & NA & $6 / 18(34 \%)$ & 18/18 (100\%) \\
\hline
\end{tabular}

EEA: endoscopic endonasal approach; TTA: transfacial/transcranial approach; RT: adjuvant radiotherapy; NA: not available data. 


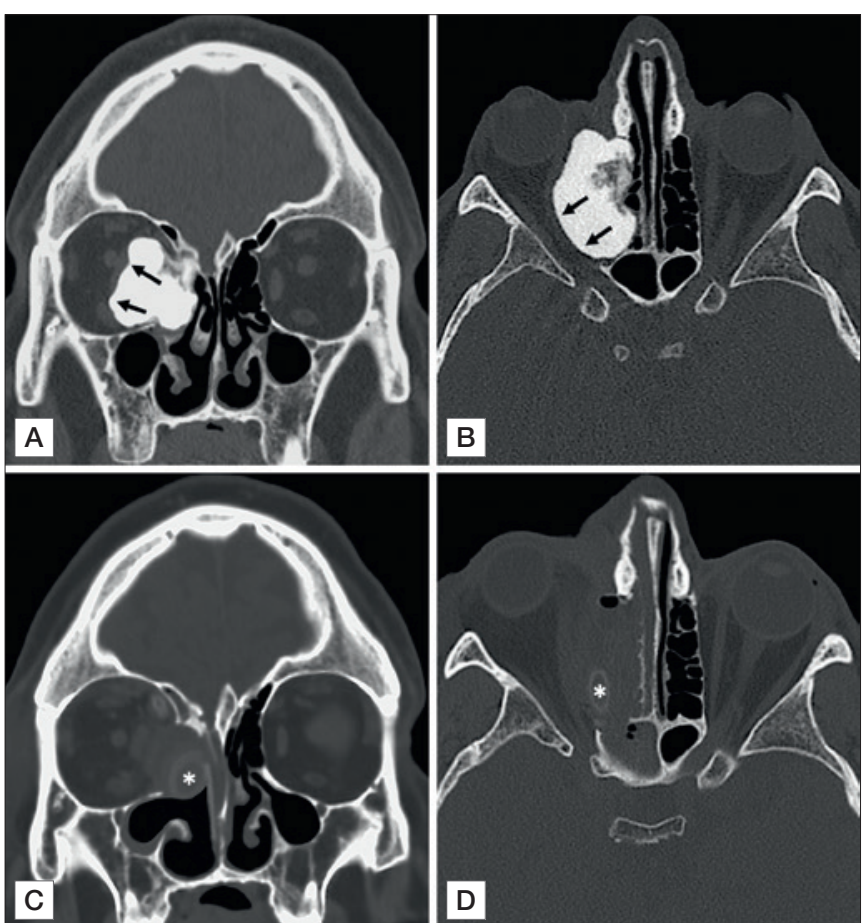

Figure 1. Coronal (A) and axial (B) CT scan of a 32 year-old male affected by ivory osteoma with right intraorbital extension. White arrows in $\mathbf{A}$ and $\mathbf{B}$ highlight the displacement of the extrinsic ocular muscles. The patient was submitted to endoscopic endonasal resection of the lesion using the cavitation technique. The early post-operative CT scan performed 24 hours after surgery (panels $\mathbf{C}$ and $\mathbf{D}$ ) ruled out any intraorbital complication. White asterisks in C and $\mathbf{D}$ indicate silicon roll sheets placed to maintain the orbital content within the orbital cavity and therefore prevent postoperative sequelae.

without needing to expose all the external boundaries of the lesion (Fig. 1), which could be selectively separated from the orbital periosteum and carefully collapsed and removed ${ }^{11,12}$. Nevertheless, additional external approaches may be required when the tumor extends anteriorly to the nasolacrimal duct or in cases of fronto-orbital tumors not easily manageable with an exclusive endoscopic treatment, as described by Georgalas et al. ${ }^{8}$. In order to achieve complete resection, different approaches through different orbital structures (eyelid, eyebrow, conjunctiva) were successfully employed with minimal residual morbidity and aesthetic defects. In cases with massive involvement of the anterior and/or posterior wall of the frontal sinus, an osteoplastic flap or Riedel-Mosher approach is necessary to reach a complete and safe surgical excision. This is the reason why a teamwork including maxillofacial surgeons, neurosurgeons and ophthalmologists is generally required. Generally, no reconstruction of the orbital walls is performed, except in case of massive removal of the bony orbital floor (more than 50\%) ${ }^{8}$. A limited intranasal herniation of the orbital content may occur but the preservation of the periorbital layer prevents diplopia, enophthalmos, or facial deformity; however, in case of major removal of the periorbit or in extensive intraorbital dissection, the placement of a silastic sheet as a protection while pushing the orbital content into the orbital cavity may be sufficient to avoid postsurgical orbital complications and the need for secondary revision surgeries ${ }^{13}$. In some cases of fibrous dysplasia, the lesion may involve the optic canal and orbital apex with optic nerve compression, resulting in progressive loss of visual acuity, color vision and peripheral and central field defects. Although elective surgery is not indicated for asymptomatic cases of optic nerve encasement, due to the potential risk of impaired optic nerve function, an immediate referral for surgical optic nerve decompression should be recommended if there is evidence of visual loss and periodic follow-up is essential to monitor any recurrences ${ }^{10,14}$. It appears clear that such critical patients should be managed in a multidisciplinary way, by means of periodical radiological, ophthalmological and surgical evaluations to define the best treatment strategy.

\section{Inverted papilloma (IP)}

Sinonasal IP may invade the orbit in 2-4\% of cases, involving frequently also the nasolacrimal system. However, especially in huge tumors spreading into the orbit, it's difficult to define whether the IP has been originated from the lacrimal structures or from the paranasal sinuses, since the nasolacrimal duct also represents one of the most common route of diffusion of sinonasal tumors to the orbit ${ }^{15,16}$. In the largest case-series of IPs invading the orbit currently available in literature, 10 cases were described and foci of malignant transformation were found in all cases, respectively six squamous cell carcinomas and four transitional cell carcinomas ${ }^{15}$. The high rate of malignant transformation observed in IP involving the orbit was confirmed also by other authors reporting smaller case-series ${ }^{17-19}$. Having in mind these critical issues, when dealing with a histologically-proven IP that shows an intraorbital extension at the preoperative MRI, one should keep in mind the possibility that this lesion might harbor foci of malignant transformation. Although in literature the mean recurrence rate is around 5-10\% for sinonasal IPs ${ }^{18}$, when the tumor invades the orbit the reported incidence of recurrence is considerably higher, ranging from 20 to $80 \%{ }^{18,19}$. This finding can be explained by the more frequent occurrence of malignant transformation compared to other IPs. In this regard, Johnson et al. ${ }^{17}$ reported four cases of IP with orbital invasion, of whom three experienced recurrences after the initial surgery in a period ranging from 4 months to 6 years; similarly, Elner et al. ${ }^{15}$ described a recurrence rate of $80 \%$ in a series of 10 cases. Considering such significant rates of 
recurrences, a multidisciplinary approach is recommended when dealing with sinonasal IPs invading the orbit. The radiologist should be consulted in order to exactly define the grade of orbital involvement and signs of clear infiltration; the pathologist plays a crucial role in analyzing the surgical specimen to find out possible signs of malignant transformation; medical and radiation oncologists should be also included in the design of treatment's strategy whenever cancerization is detected. Few data are available in the current literature about the proper surgical management of these tumors but, taking into account their aggressive behavior, there is a general consensus that aggressive surgical resection is recommended in order to obtain complete removal of the lesion. Radical surgical treatment, even including orbital exenteration, may be required (Fig. 2) ${ }^{15,18}$. No evidences are currently available regarding indications for adjuvant treatments in such cases; however, some authors suggested the importance of adjuvant radiotherapy in case of orbital involvement by an IP harboring signs of malignant transformation in order to improve long-term local control of disease ${ }^{20,21}$.

\section{Juvenile angiofibroma (JA)}

This vascular tumor is supposed to originate from vascular embryonic remnants in the cancellous bone around the vidian canal and basisphenoid, typically showing an expansive and destructive pattern of growth with spread to adjacent anatomical compartments throughout foramina and fissures. Tumoral extension to the orbit, across the inferior orbital fissure, turns out to be a common finding in advanced staged lesions, ranging from 27 to $32 \%$ of cases ${ }^{22}$. Ophthalmological disorders and visual defects are caused by direct compression of the eye, optic nerve and chiasm, with proptosis reported as the most frequent symptom ${ }^{23}$. Considering that JA is a vascular lesion and its surgical removal carries a high risk of profuse bleeding, preoperative embolization is advised in advanced-stage cases, paying special attention to the feeding vessels coming from the internal carotid artery (ICA) which can be more frequently involved when the JA extends to the orbital compartment. Xu et al. ${ }^{23}$, in a series of 18 patients affected by JA involving the orbit and optic nerve, described the occurrence of blood supply to the tumor from small arterial vessels branching from the ophthalmic artery, which should be properly recognized by the interventional radiologist and not embolized, in order to avoid vision loss due to central retinal artery occlusion ${ }^{24}$. Different treatment strategies have been proposed in the last decades, such as radiotherapy, chemotherapy and hormone therapy, with little or no success. Surgical excision is considered as the best treatment option, aiming complete tumor excision to avoid persistent disease and therefore
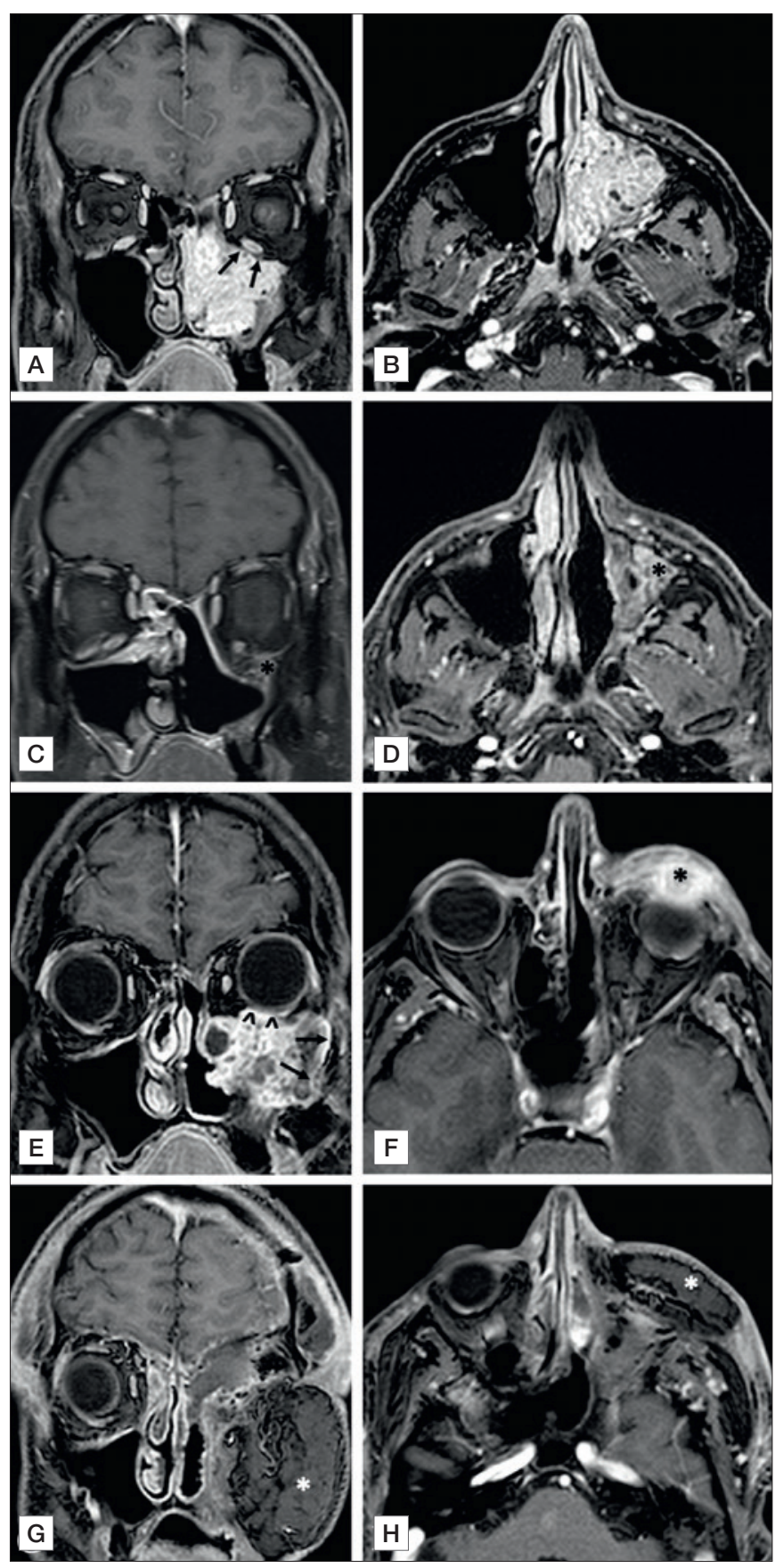

Figure 2. Contrast-enhanced MRI in coronal (A) and axial views (B) of a 46 year-old man affected by left ethmoid-maxillary inverted papilloma eroding the floor of the left orbit (black arrow in A), who underwent endoscopic endonasal resection with left medial maxillectomy type III. Postoperative MRI (C and D) excluded residual disease with hyperintense signal (black asterisk) at the left orbital floor, interpreted as post-surgical scar tissue requiring close radiological follow up. MRI performed 3 months after the surgery ( $E$ and $\mathbf{F}$ ) demonstrated an extensive recurrence of disease involving the orbital floor (black arrowheads in $\mathbf{E}$ ), anterior orbital content (black asterisk in $\mathrm{F}$ ), hard palate and lateral bony wall of the left maxilla (black arrows in $\mathbf{E}$ ), thus the patient was submitted to transfacial radical maxillectomy associated with orbital exenteration and reconstruction with an anterolateral thigh (ALT) flap. Final histology revealed an invasive SSC arising on IP. The MRI performed 3 years after the surgery ( $\mathbf{G}$ and H) excluded local recurrences of disease (white asterisks indicate ALT flap). 
minimize recurrence rates. Nowadays, the increase of endoscopic surgical skills together with advances in surgical instrumentation, imaging and intraoperative surgical navigation systems allows a minimally invasive endoscopic endonasal resection even in advanced staged lesions, like those with orbital involvement. Compared to traditional transfacial approaches, the endoscopic endonasal surgery improves surgical results, with limited blood loss, reduced postoperative sequelae and minimized recurrence rates ${ }^{25-28}$. In the surgical management of JA involving the orbit and orbital apex, particular care must be taken to avoid injury of the optic nerve, III, V2, and V1 cranial nerves. Similarly, adequate endoscopic surgical skills are required in order to manage intraoperative bleeding, especially for tumor feeders originating from the ophthalmic artery, which should be coagulated without damaging any intraorbital neurovascular structures.

Another crucial aspect is the management of a recurrent or persistent intraorbital JA, since tumoral regrowth in such areas has not been described frequently in literature and small remnants might undergo an involution over time. Therefore, in case of a partial resection with a stable asymptomatic intraorbital JA persistence (e.g. inferior orbital fissure), there is not a strict indication for an immediate revision surgery unless there is measurable tumor growth or new symptoms ${ }^{26}$.

In the light of all these aspects, JAs should be treated in tertiary-care referral centers, specialized in skull base surgery, by a multidisciplinary team including ENT surgeon, neurosurgeons, ophthalmologist, neuroradiologists and interventional radiologists, in order to achieve best results in terms of complete resection and low morbidity for the patient.

\section{Malignant tumors}

Malignant sinonasal tumors are extremely rare, accounting about 3\% of all head and neck tumors and less than $1 \%$ of all malignant neoplasms. They include a variety of different histotypes with different behaviors, survival outcomes and treatment protocols ${ }^{29-31}$. The most frequentely encountered are squamous cell carcinoma, intestinal type adenocarcinoma (ITAC), esthesioneuroblatoma (ENB) and sinonasal undifferentiated carcinoma (SNUC) ${ }^{32}$.

Sinonasal tumors are frequently diagnosed in advanced stages due to their delayed symptoms that easily mimick inflammatory diseases. The incidence of orbital invasion by sinonasal malignancies depends on the site of origin, histology, and aggressiveness of the specific tumor and it is reported between 62 and $82 \%$ of all ethmoidal tumors, $55 \%$ of maxillary neoplasms, and $46 \%$ of nasal cavity tumors ${ }^{33}$. Tumors may invade the orbit through preformed pathways (nasolacrimal duct, orbital fissures, optic canal, ethmoidal foramina), neurovascular structures (infra- e supraorbital nerves) or by direct invasion transgressing surrounding bones (e.g. erosion of the lamina papyracea in most cases) ${ }^{3,6}$. This condition inevitably impacts on survival rate, functional outcomes and therapeutic strategies. It has been widely accepted that the grade of orbital infiltration strongly impacts on prognosis, with worst survival rates in case of extensive orbital involvement ${ }^{3,34}$. Different case series in literature reported 5-year disease free survival of $69 \%$ for tumors abutting the lamina papyracea, $51 \%$ for tumors invading the periorbital layer, $34 \%$ for tumors involving the orbital content and, lastly, down to nearly $0 \%$ in case of orbital apex involvement ${ }^{3}$.

\section{Grade of orbital invasion}

Orbital invasion must be preoperatively graded, by means of an accurate radiological imaging, as minimal (erosion of lamina papyracea, loss of the fat plane between tumor and extraconal muscles, periorbital irregularities) or massive, often accompanied by clinical signs of orbital involvement (proptosis, visual loss, restriction of ocular motility) ${ }^{35}$. The recent $8^{\text {th }}$ edition of the AJCC (American Joint Committee on Cancer) cancer staging system considers orbit involvement as a significant factor upgrading tumor classification: tumor is staged as T3 when invasion is limited to orbital bony wall, as T4a in case of invasion of the anterior orbital contents, and as T4b when the orbital apex is involved. The lack of an officially recognized classification defining the depth of orbital involvement by the tumor poses some challenges. Firstly, comparison of results from different studies can be challenging ${ }^{29}$. Secondly, the lack of a clear definition as to what constitutes orbital invasion has been a source of confusion, and an accurate distinction should be made between bony erosion, orbital soft tissues involvement and apex infiltration. Thirdly, considering that surgical resection has always been considered as the cornerstone in the management of sinonasal tumors invading the orbit, a recognized classification is needed in order to correctly define indications whether to preserve or exenterate the orbit. In fact, orbital exenteration appears to be an invasive procedure conditioning a significant functional defect, esthetic deformity and, consequently, emotional impact ${ }^{29}$. Over the years, different classifications have been proposed, aimed to stratify patients according to tumor aggressiveness and to guide adequate treatment planning (Tab. II) ${ }^{3,33,36,37}$. Current indications for orbital exenteration are: gross orbital contents invasion; extensive infiltration of the extraconal fat, extraocular muscles; intraconal and retrobulbar fat invasion; eye bulb and optic nerve involvement; bulbar conjunctiva or sclera, eyelid, and/or proximal lacrimal path- 
Table II. Grading systems of orbital invasion and relative treatments.

\begin{tabular}{|c|c|c|c|}
\hline Author, year of publication & & Grading of orbital invasion & Treatment \\
\hline \multirow[t]{4}{*}{ McCary et al., $1996{ }^{35}$} & A & $\begin{array}{l}\text { Tumor adjacent the orbit without infiltration of the orbital } \\
\text { wall }\end{array}$ & $\mathrm{RT} / \mathrm{CT}+$ surgery \\
\hline & B & $\begin{array}{c}\text { Tumor eroding the orbital wall without ocular bulb } \\
\text { displacement }\end{array}$ & \\
\hline & C & $\begin{array}{c}\text { Tumor eroding, infiltrating and displacing the orbital wall } \\
\text { without periorbital invasion }\end{array}$ & \\
\hline & $\mathrm{D}$ & Tumor invading the orbit with periorbital invasion & $\begin{array}{l}\text { RT/CT + surgery with resection of } \\
\text { involved periorbita (exenteration if } \\
\text { extensive involvement) }\end{array}$ \\
\hline \multirow[t]{3}{*}{ lannetti et al., $2005^{36}$} & 1 & Erosion or destruction of medial orbital wall & Resection of medial orbital wall \\
\hline & 2 & Extraconal invasion of periorbital fat & \\
\hline & 3 & $\begin{array}{c}\text { Invasion of medial rectal muscle, optic nerve, ocular bulb } \\
\text { or skin overlying the eyelid }\end{array}$ & Orbital exenteration \\
\hline \multirow[t]{5}{*}{ Neel et al., $2016^{32}$} & 1 & $\begin{array}{l}\text { Tumor adjacent to orbital wall, which may be thinned, } \\
\text { bowed or eroded without periorbital invasion }\end{array}$ & $\begin{array}{l}\text { Drilling and resection of involved } \\
\text { bone }\end{array}$ \\
\hline & 2 & $\begin{array}{c}\text { Tumor eroding the orbital wall, with resectable periorbital } \\
\text { involvement }\end{array}$ & $\begin{array}{l}\text { Resection of periorbita and } \\
\text { underlying extraconal orbital fat }\end{array}$ \\
\hline & 3 & $\begin{array}{c}\text { Tumor with extraocular muscle, intraconal fat, globe or } \\
\text { orbital apex invasion }\end{array}$ & Orbital clearance \\
\hline & 4 & $\begin{array}{l}\text { Tumor invading the nasolacrimal system, eyelids duct } \\
\text { and/or sac }\end{array}$ & Orbital exenteration \\
\hline & 5 & $\begin{array}{c}\text { Tumor with cavernous sinus, optic canal or massive } \\
\text { intracranial invasion }\end{array}$ & Unresectable, pallation \\
\hline \multirow[t]{4}{*}{ Turri-Zanoni et al., $2018^{3}$} & 1 & Erosion or destruction of lamina papyracea & Endoscopic endonasal surgery \\
\hline & 2 & $\begin{array}{c}\text { Invasion of the periorbital layer and/or focal invasion of } \\
\text { the extraconic periorbital fat }\end{array}$ & \\
\hline & 3 & Invasion of the anterior $2 / 3$ of the orbit & Orbital exenteration \\
\hline & 4 & Involvement of the orbital apex & Unresectable, palliation \\
\hline
\end{tabular}

RT: radiotherapy; CT: chemotherapy.

ways infiltration. Although orbital apex involvement has been considered in the last decades as an indication to orbital exenteration ${ }^{6,30,33}$, recent scientific reports found that, in such cases, prognosis remains poor regardless the extent of surgery and, in general, any kind of multimodal treatment adopted ${ }^{3}$. Thus, current trends tend to exclude orbital exenteration when orbital apex is massively involved by the cancer.

\section{Management of sinonasal tumors invading the orbit}

The gold standard treatment of sinonasal malignancies invading the orbit still remains controversial, and it has been widely debated in recent literature. The main reasons are the small amount of available data and the lack of a standardized universally-accepted classification of orbital invasion, as previously mentioned ${ }^{29}$. Traditionally, the standard treatment of sinonasal tumors invading the orbit was radical excision with orbital exenteration ${ }^{1}$. In recent years, increased attention to patient's quality of life, the refinement of minimally invasive endoscopic techniques and the devel- opment of multimodal treatment protocols have led to significant progress in managing such patients, with an evergrowing trend to orbital preservation. Currently, available treatments include surgical removal (via pure endoscopic surgery or open endoscopic-assisted surgery), chemotherapy in an induction or adjuvant setting, and adjuvant radiotherapy. All these therapeutic options must be previously discussed during a multidisciplinary tumor board ${ }^{3,33}$.

Based on these assumptions, a histology-driven treatment algorithm has been proposed (Fig. 3) in order to offer tailored therapies to high-grade tumors (poorly differentiated squamous cell carcinoma, neuroendocrine carcinoma, esthesioneuroblastoma Hyams grade IV, sinonasal undifferentiated carcinoma, ITAC p53 wild type) and other specific treatments to well differentiated malignancies (adenocarcinoma, adenoid cystic carcinoma, low-grade esthesioneuroblastoma and squamous cell carcinoma) and to chemoresistant tumors (mucosal melanoma) ${ }^{3}$. High-grade tumors might be submitted to induction chemotherapy ${ }^{30}$, up to a maximum of five cycles, conducted with different protocols 


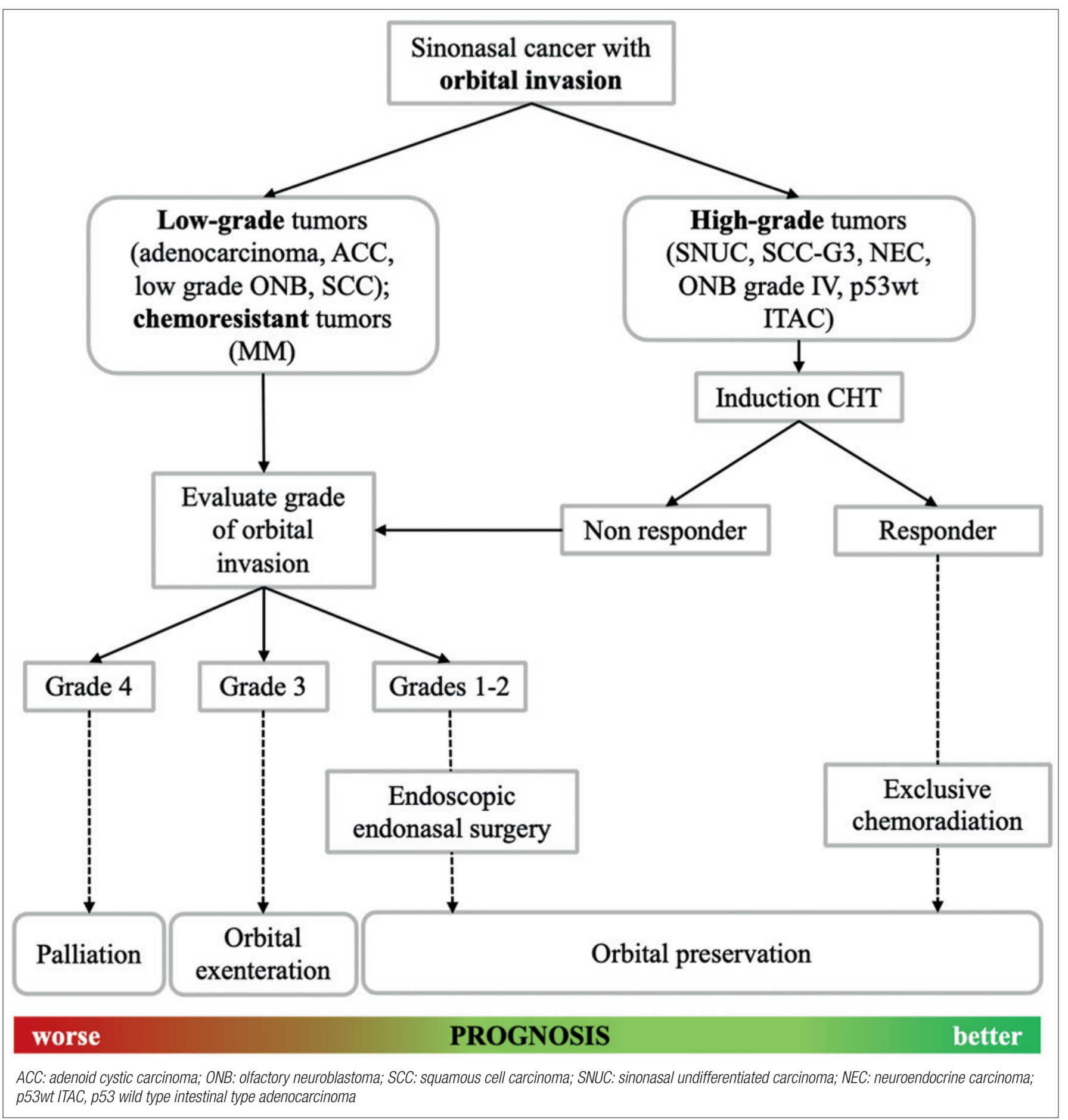

Figure 3. Flowchart describing the multimodal management of sinonasal cancers with orbital invasion.

based on the specific histotype (TPF, PE/AI regimen, PFL regimen) ${ }^{3}$; the response rate to induction chemotherapy is radiologically evaluated by seriated contrast-enhanced MRI and can be used to segregate "good responders" from "non-responders". Patients achieving complete or good response ( $>80 \%$ reduction of initial tumor volume) can be treated with exclusive orbital-sparing chemoradiation with curative intent (Fig. 4). Conversely, patients achieving partial response (tumor reduction inferior to 80\%), non-responder patients (reduction inferior to $30 \%$ ), and pa- 

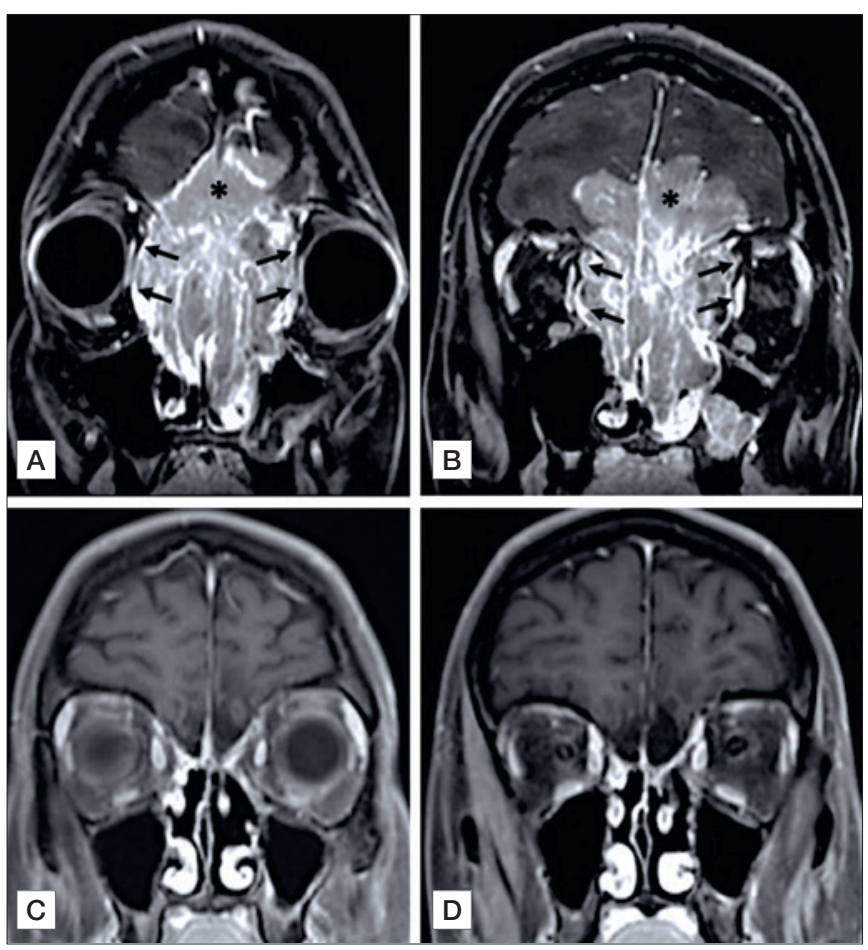

Figure 4. Contrast-enhanced MRI in coronal views (panels $\mathbf{A}$ and $\mathbf{B}$ ) of a 30 year-old female affected by poorly-differentiated small cells neuroendocrine carcinoma, with intracranial involvement (black asterisk) and bilateral orbital invasion (black arrows). The patient received induction chemotherapy (cisplatin/etoposide scheme, 5 cycles) with complete response. The patient was therefore submitted to exclusive chemoradiation with curative intent. The contrast-enhanced MRI performed 2 years after treatment excluded recurrences of disease (C and $\mathbf{D})$.

tients with disease progression might be directed to surgical resection, followed by adjuvant radiotherapy or chemoradiation (Fig. 5). On the other hand, patients affected by low-grade tumors, chemoresistant tumors, and high-grade tumors non-susceptible to systemic chemotherapy due to age and/or severe comorbidities, can be submitted to upfront surgery. When a surgical resection is planned, an endoscopic endonasal approach must be preferred when feasible, eventually combined with a traditional transfacial or craniofacial surgery in case of massive intracranial or facial skeleton involvement, always respecting the oncological principle of complete excision. The surgical management and the decision whether to preserve or exenterate the orbit, must be carefully discussed and planned according to the extent of orbital invasion. In case of limited orbital involvement (tumor abutting the orbital bones, erosion of lamina papyracea, orbital periosteum, minimal extraconal fat infiltration), an orbital-sparing endoscopic surgery might be adopted and intraoperative frozen sections examination should be used to assess the free-margins resection. Conversely, orbital exenteration should be planned in case of
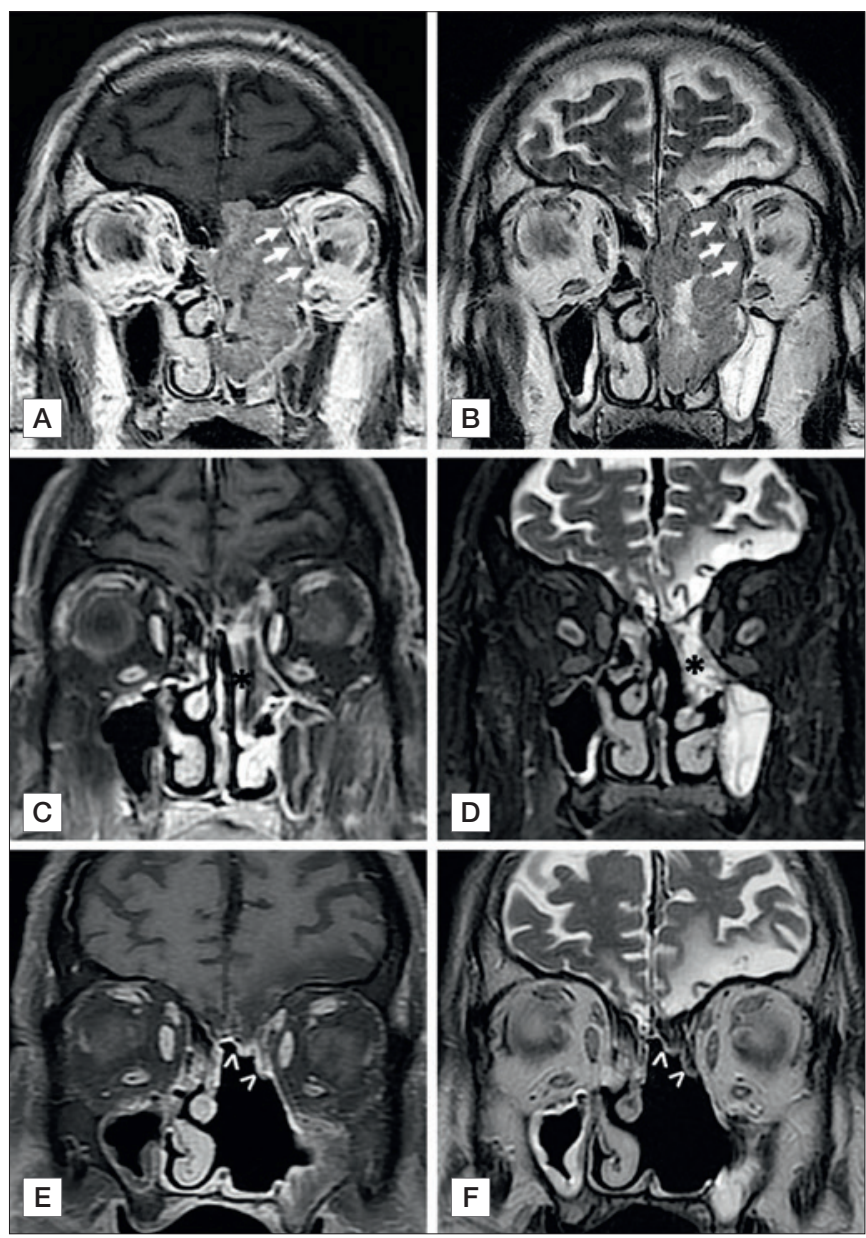

Figure 5. Contrast-enhanced MRI in coronal views ( $A$ and $\mathbf{B}$ ) of a 69 year-old man affected by locally advanced sinonasal undifferentiated carcinoma involving the left orbit (white arrows). The patient underwent induction chemotherapy (TPF scheme, 5 cycles) obtaining partial response (black asterisks in panels $\mathbf{C}$ and $\mathbf{D}$ indicate the persistence of disease). A left unilateral endoscopic resection with transnasal craniectomy and skull base reconstruction (white arrowheads) was performed to remove the residual disease. Finally, the patient received adjuvant irradiation using intensity-modulated radiotherapy (62 Gy). The contrast-enhanced MRI performed 5 years after treatment showed no evidence of disease ( $\mathbf{E}$ and $\mathbf{F}$ ).

extensive invasion of the extraconal fat, extraocular muscles, intraconal and retrobulbar fat invasion, eye bulb and optic nerve involvement, bulbar conjunctiva or sclera infiltration, eyelid involvement, proximal lacrimal pathways invasion $^{3,30}$ (Fig. 6). When dealing with such advanced-stage sinonasal tumors, a postoperative radio(chemo)therapy is adopted almost invariably, according to the final histology report. Orbital apex infiltration by sinonasal cancer deserves separate consideration since it has been reported how orbital apex involvement is dramatically related to poor prognosis regardless the treatment strategy adopted and extent of surgery ${ }^{3}$. A free-margins resection is virtually 

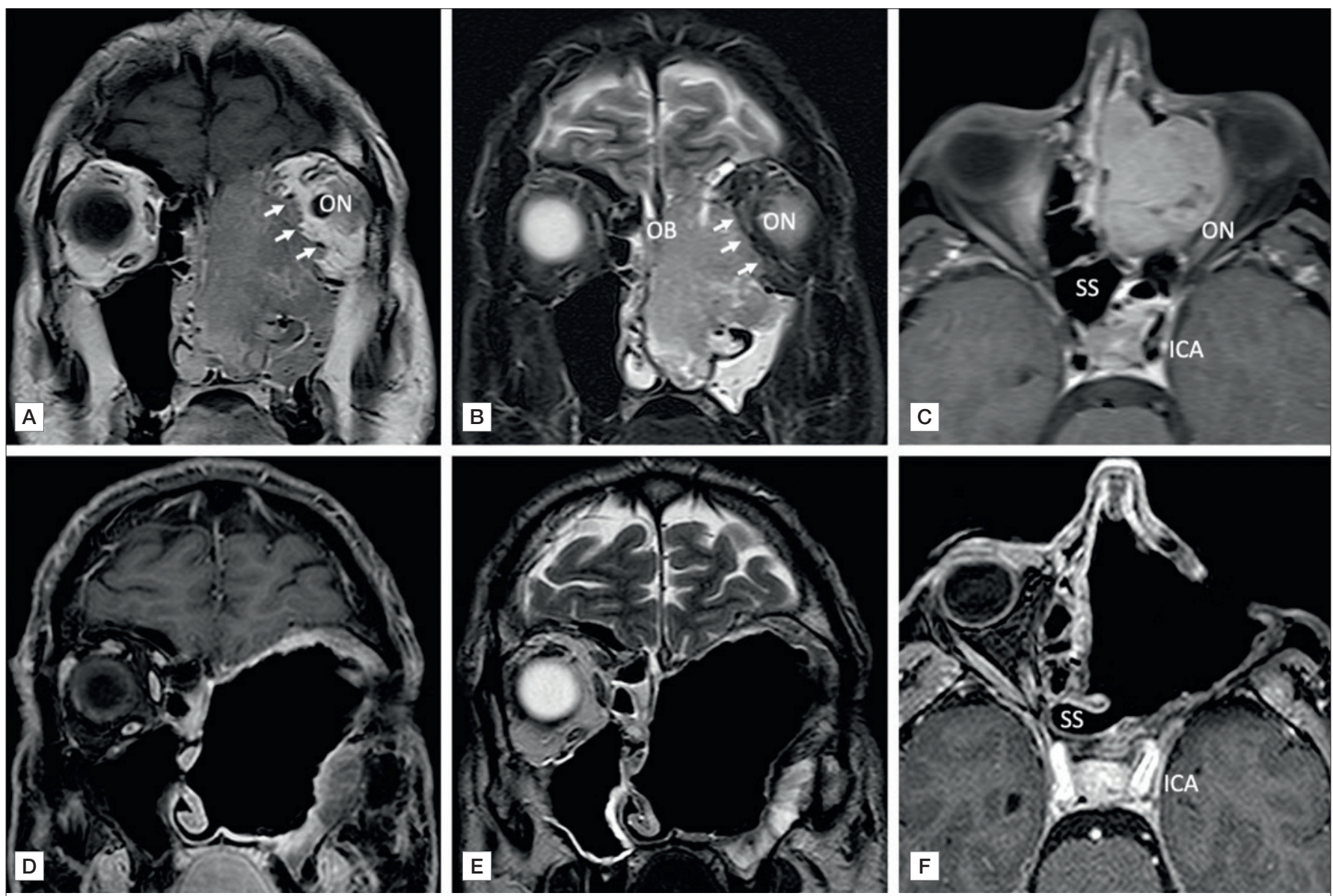

Abbreviations: ON: optic nerve; OB: olfactory bulb; SS: sphenoid sinus; ICA: internal carotid artery

Figure 6. Contrast-enhanced MRI in coronal (A, T1 contrast-weighted and B, T2-weighted sequences) and axial (C, T1 contrast-weighted) views of a 51 yearold man affected by locally advanced well-differentiated squamous cell carcinoma involving the left orbit (white arrows indicate medial and inferior rectus muscles infiltration) and encroaching the anterior skull base. The patient underwent a bilateral endoscopic endonasal resection associated with skull base reconstruction and left orbital exenteration, followed by adjuvant irradiation (66 Gy). The contrast-enhanced MRI performed 3 years after treatment excluded recurrences of disease (panels $\mathbf{D}$, E and $\mathbf{F}$ ).

impossible in such cases due to the complex neurovascular anatomy of this site. Indeed, in such advanced cases, curative treatments are excluded and different forms of palliative surgery and/or chemoradiation should be adopted ${ }^{3}$. Tumors with cavernous sinus invasion, internal carotid artery encasement or massive intracranial involvement should be considered unresectable as well ${ }^{33,38}$.

\section{Prognostic significance of orbital invasion}

To date, it is widely accepted that orbital invasion by sinonasal tumors affects negatively the survival rates, as summarized by data emerging from the largest case-series currently available in literature (Tab. III). Several worldwide case series have supported the evidence that progressive involvement of the orbital structures decreases survival rates ${ }^{38-40}$. Suarez et al. reported disease-specific survival rates of $41 \%$ in patients affected by sinonasal cancers with orbital invasion compared to $75 \%$ for those without orbital involvement ${ }^{38}$. Although a clear consensus regarding the oncological safety of orbital preservation has not yet been reached, trends encouraging orbit-sparing surgery are renowned since many years. In this regard, Carrau et al. found that orbit preservation, when a full-thickness periorbit infiltration was excluded, did not downgrade oncological outcomes, while a full-thickness periorbit invasion was associated with a decreased prognosis. Their results suggested that eye preservation, in the absence of orbital soft tissues invasion, did not compromise the local control rate $^{4}$. In 2002, Imola and Schramm reported no differences in terms of survival rates between orbital preservation and 
Table III. Literature review.

\begin{tabular}{|c|c|c|c|c|c|}
\hline Authors & $\begin{array}{l}\text { N. of } \\
\text { cases }\end{array}$ & $\begin{array}{l}\text { Degree of } \\
\text { orbital invasion }\end{array}$ & $\begin{array}{l}\text { Treatment } \\
\text { strategies }\end{array}$ & $\begin{array}{l}\text { Oncological } \\
\text { outcomes }\end{array}$ & Conclusions \\
\hline $\begin{array}{l}\text { Carrau } \\
1999^{4}\end{array}$ & 58 & $\begin{array}{l}36 \% \text { orbital invasion (bone } \\
\text { and soft tissues) }\end{array}$ & $\begin{array}{l}\text { Surgical resection + } \\
\text { adjuvant treatment }\end{array}$ & $\begin{array}{l}\text { NED } 56 \% \text { cases after orbital } \\
\text { preservation } \\
\text { NED } 50 \% \text { cases after orbital } \\
\text { exenteration }\end{array}$ & $\begin{array}{l}\text { Orbital sparing is possible } \\
\text { when soft tissues are } \\
\text { uninvolved, without affecting } \\
\text { oncological outcomes }\end{array}$ \\
\hline $\begin{array}{l}\text { Imola and } \\
\text { Schramm } \\
2002^{40}\end{array}$ & 66 & $\begin{array}{l}54 \text { pt with bony wall or } \\
\text { periorbital involvement } \\
12 \text { pt with intraorbital } \\
\text { involvement }\end{array}$ & $\begin{array}{c}\text { Surgery } \\
\text { poRT in } 44 \text { cases }\end{array}$ & $\begin{array}{l}\text { LRR } 29.6 \% \text { after orbital preservation } \\
\text { LRR } 33.3 \% \text { after orbital exenteration }\end{array}$ & $\begin{array}{l}\text { Selective orbital preservation } \\
\text { does not seem to adversely } \\
\text { affect survival or local control }\end{array}$ \\
\hline $\begin{array}{l}\text { lannetti } \\
2005^{36}\end{array}$ & 29 & $\begin{array}{l}24.1 \% \text { medial orbital wall } \\
\text { invasion } \\
\begin{array}{l}20.7 \% \text { extraconal fat } \\
\text { invasion }\end{array} \\
\begin{array}{l}37.9 \% \text { intraconal or eyelid } \\
\text { skin invasion }\end{array}\end{array}$ & $\begin{array}{c}\text { CFS } \\
\text { poRT } 37.9 \%\end{array}$ & $\begin{array}{c}\text { 5y OS } 71.4 \% \text { with medial orbital wall } \\
\text { invasion } \\
\begin{array}{c}5 y \text { OS } 33.3 \% \text { with extraconal fat } \\
\text { invasion }\end{array} \\
\text { 5y OS } 50.9 \% \text { with intraconal fat } \\
\text { invasion }\end{array}$ & $\begin{array}{l}\text { Orbital exenteration is } \\
\text { necessary in case of intraconal } \\
\text { fat invasion }\end{array}$ \\
\hline $\begin{array}{l}\text { Ganly } \\
2005^{49}\end{array}$ & 334 & $\begin{array}{c}33.8 \% \text { bone } \\
16.5 \% \text { periosteum } \\
15 \% \text { orbital contents }\end{array}$ & $\begin{array}{c}\text { CFS } \\
\text { poRT } 48 \%\end{array}$ & $\begin{array}{l}\text { 5y DSS } 75 \% \text { with no orbital invasion } \\
\text { 5y DSS } 40.7 \% \text { with bone/periosteum } \\
\text { invasion } \\
\text { 5y DSS } 44.4 \% \text { with intraorbital } \\
\text { invasion }\end{array}$ & $\begin{array}{l}\text { Orbital contents invasion was } \\
\text { a negative PF in univariate } \\
\text { analysis, but not statistically } \\
\text { significant in multivariate } \\
\text { analysis }\end{array}$ \\
\hline $\begin{array}{l}\text { Patel } \\
2003^{38}\end{array}$ & 1306 & $\begin{array}{c}24.6 \% \text { bone } \\
\text { 10.5\% periosteum } \\
22.5 \% \text { orbital content }\end{array}$ & $\begin{array}{c}\text { CFS } \\
\text { poRT 39\% }\end{array}$ & $\begin{array}{c}\text { 5y DSS } \begin{array}{c}66.2 \% \text { with no orbital } \\
\text { invasion }\end{array} \\
\begin{array}{c}5 y \text { DSS } 59.2 \% \text { with bone/periosteal } \\
\text { invasion }\end{array} \\
\begin{array}{c}5 y \text { DSS } 48.2 \% \text { with orbital contents } \\
\text { invasion }\end{array}\end{array}$ & $\begin{array}{l}\text { Orbital contents invasion is } \\
\text { a negative PF in univariate } \\
\text { analysis, but not statistically } \\
\text { significant in multivariate } \\
\text { analysis }\end{array}$ \\
\hline $\begin{array}{l}\text { Howard } \\
2006^{39}\end{array}$ & 308 & $\begin{array}{l}\text { No orbital involvement in } \\
56 \% \text { of pt }\end{array}$ & $\begin{array}{c}\text { CFS } \\
\text { Adjuvant treatment } 40 \% \\
\text { (mainly RT) }\end{array}$ & $\begin{array}{l}\text { 5y OS 52\% with no orbital } \\
\text { involvement } \\
\text { 5y OS } 45 \% \text { with periosteal invasion } \\
\text { 5y OS 14\% with orbital involvement }\end{array}$ & Orbital spread is a negative PF \\
\hline $\begin{array}{l}\text { Suarez } \\
2004^{37}\end{array}$ & 100 & $\begin{array}{l}36 \% \text { periosteum } \\
14 \% \text { deep orbital } \\
\text { involvement }\end{array}$ & $\begin{array}{c}\text { CFS } \\
\text { Adjuvant treatment 55\% } \\
\text { (mainly RT) }\end{array}$ & $\begin{array}{c}\text { 5y OS } 44 \% \text { with no deep orbital } \\
\text { invasion }\end{array}$ & $\begin{array}{c}\text { Deep orbital involvement is a } \\
\text { negative PF }\end{array}$ \\
\hline $\begin{array}{l}\text { Safi } \\
2017^{28}\end{array}$ & 52 & $\begin{array}{l}100 \% \text { invading the orbit } \\
\text { beyond orbital periosteum }\end{array}$ & $\begin{array}{c}\text { CFS } \\
\text { Surgery + poRT }\end{array}$ & $\begin{array}{c}\text { 5y OS 14\% after orbital preservation } \\
+ \text { poRT } \\
\text { 5y OS 65.5\% after orbital } \\
\text { exenteration }\end{array}$ & $\begin{array}{l}\text { In case of orbital content } \\
\text { invasion, exenteration shows } \\
\text { better survival rate than } \\
\text { conservative surgery }\end{array}$ \\
\hline $\begin{array}{l}\text { Turri-Zanoni } \\
2018^{3}\end{array}$ & 196 & $\begin{array}{l}\text { Grade 1: } 44 \text { pt } \\
\text { Grade 2: } 46 \text { pt } \\
\text { Grade 3: } 49 \mathrm{pt} \\
\text { Grade 4: } 24 \mathrm{pt}\end{array}$ & $\begin{array}{c}27 \text { pt orb. exenteration } \\
112 \text { pt orb. preservation } \\
5 \text { cases treated with CTRT } \\
\text { Grade } 4 \text { patients: } \\
11 \text { pt orb. exenteration } \\
13 \text { pt orb. preservation }\end{array}$ & $\begin{array}{l}\text { 5y OS } 84 \% \text { for grade } 1 \\
\text { 5y OS } 64.1 \% \text { for grade } 2 \\
\text { 5y OS } 48.9 \% \text { for grade } 3 \\
\text { 5y OS } 14.6 \% \text { for grade } 4\end{array}$ & $\begin{array}{l}\text { Orbital invasion represents a } \\
\text { negative prognostic factor. } \\
\text { Neoadjuvant chemotherapy can } \\
\text { downstage the local extension } \\
\text { of the tumor and maximize } \\
\text { orbital preservation rates } \\
\text { Cancers invading the orbital } \\
\text { apex must be considered } \\
\text { incurable }\end{array}$ \\
\hline
\end{tabular}

CFS: craniofacial surgery; RT: radiotherapy; poRT: postoperative radiotherapy; preRT: preoperative radioteraphy; CT: chemotherapy; CTRT: chemoradiotherapy; LRR: Iocal recurrence rate; LCR: local control rate; DSS: disease specific survival; OS: overall survival; NED: non evidence of disease; PF: prognostic factor. 
orbital exenteration in patients with tumor invasion limited to the bony orbital walls ${ }^{41}$. In 2006, Howard et al., as well, demonstrated that patients with preserved orbit didn't have worst prognosis when the orbital periosteum was not breached yet by the tumor; thus, removal of the infiltrated periorbit with the conservation of the orbital content could be oncologically feasible ${ }^{40}$. Therefore, sparing the soft tissues of the orbit when the periorbit have not been deeply transgressed by the tumor generally does not appear to adversely affect cure or local control ${ }^{38}$. On the other hand, when dealing with advanced-stage tumors with invasion of the orbit beyond the orbital periosteum, the orbital exenteration is considered as a safe oncological procedure with better oncological rates than conservative surgery ${ }^{29}$. In addition, recent reports have shown how orbital apex involvement appeared to be an independent prognostic factor, negatively impacting the survival rates and precluding any kind of curative treatment ${ }^{3,33,42}$. Turri-Zanoni et al. described 24 patients with orbital apex infiltration by sinonasal cancer, reporting a $95.8 \%$ rate of recurrence and death from disease within a mean period of 21 months ${ }^{3}$. Similarly, Nishino et al. described oncologic outcomes of multimodality treatments for patients with advanced-stage malignant tumors with orbital invasion, reporting significantly worse local control rates in patients with disease involving the orbital apex ${ }^{42}$. In conclusion, a multidisciplinary approach is mandatory for the correct management of sinonasal cancers invading the orbit and to thoroughly define precise indications to orbital exenteration.

\section{Reconstruction of orbital defects}

The main reconstructive goal is the support and positioning of the preserved eye, since it sits adjacent to the airfilled cavities of the maxillary, ethmoid and frontal sinuses. Other objectives are aesthetic restoration of bony and soft tissue defects, and skull base reconstruction of associated dural defects, when present ${ }^{43}$. Reconstructive options range from no reconstruction to grafts positioning, and, in selected cases, to free flap transfer, based on the extent of resection. Immediate reconstruction is recommended in order to improve healing and mitigate soft tissue contraction, especially if radiation therapy has or will be administered. Isolated papyracea defects and limited bony orbital floor defects, medial to the course of the infraorbital nerve, do not require rigid reconstruction, since the periorbit integrity itself is able to keep the position of the orbital content. Even in case of periorbital defects, the reconstruction is not routinely required since orbital stability is warranted by the intraorbital connective septal system and postoperative scar tissue is enough to restore the orbital continence ${ }^{44}$. To promote such healing process, a U-shaped silastic sheet can be placed to keep the orbital content into the orbital cavity and prevent its prolapse into the sinonasal region ${ }^{13}$. In selected cases, fascial grafts (temporalis or fascia lata), mucoperiosteum harvested from the middle turbinate or nasal floor/septum, or commercially available acellular dermis layer can be used to this purpose ${ }^{33}$. Larger defects involving the orbital floor must undergo rigid reconstruction to avoid post-operative enophthalmos, globe malposition, ptosis, diplopia and ectropion ${ }^{41}$. Titanium mesh or porous polyethylene implants can be used when post-operative irradiation is not scheduled (e.g. benign tumors) while bony free flap (e.g. scapular tip flap, iliac crest and fibular free flap) should be preferred in case of malignancies. Larger resections involving total maxillectomy, skull base removal, orbital exenteration and facial soft tissue removal require both structural and aesthetic reconstruction using distant free tissue transfer, such as chimeric anterolateral thigh flap ${ }^{45}$, radial forearm flap or rectus abdominis flap. In addition to flap, prosthetic rehabilitation can be also helpful in these cases to restore form. Secondary procedures may be required for remodeling of the flap's soft tissues and to provide adequate space where prosthetics can be applied.

\section{Functional outcomes}

Functional sequelae which may be observed in case of orbital preservation may include enophthalmos, diplopia, lid ectropion, epiphora, canthal dystopia, exposure keratitis and visual loss. Imola and Schramm described a grading system to assess the eye function, which stratified cases as follows: grade I, functional vision without impairment; grade II, functional vision with impairment (chronic ophthalmological sequelae); and grade III, nonfunctional eye (blindness, nonserviceable visual acuity, intractable diplopia, patched eye, or delayed exenteration) ${ }^{41}$. In their study on 54 patients, eye function was reported as grade I in $54 \%$, grade II in $37 \%$, and grade III in $9 \%$. The most common problem observed was orbit malposition due to lack of adequate rigid reconstruction of the orbital floor. However, the enophthalmos was not frequently associated with persistent diplopia, which was reported only in $9 \%$ of cases. Similarly, TurriZanoni et al. reported a case-series of 125 patients where the orbital preservation was achieved, obtaining functional eye without impairment in $63.2 \%$, functional with impairment in $32.8 \%$, and nonfunctional only in $4 \%{ }^{3}$. Both of these studies concluded that postoperative radiation increased the risk of orbital sequelae, especially for optic atrophy, cataract formation, eye dryness, and ectropion. This is supported also by Rajapurkar et al. who described two cases of decreased visual acuity and radiation-induced retinopathy from a series of 19 patients with preserved orbit ${ }^{46}$. 
Table IV. Summary of evidences available in literature concerning the multidisciplinarymanagement of sinonasal benign and malignant tumours with orbital invasion.

\begin{tabular}{|c|c|c|c|}
\hline Pathology & $\begin{array}{l}\text { Rate of orbital invasion } \\
\qquad(\%)\end{array}$ & $\begin{array}{l}\text { Multidisciplinary } \\
\text { management }\end{array}$ & $\begin{array}{l}\text { Orbital } \\
\text { preservation }\end{array}$ \\
\hline $\mathbb{P}$ & $2-4 \%$ & Recommended & Almost invariably \\
\hline FOLs & $12-15 \%$ & Recommended & Almost invariably \\
\hline JNA & $27-32 \%$ & Recommended & Almost invariably \\
\hline $\begin{array}{l}\text { Low grade cancer (adenocarcinoma, } A C C \text {, } \\
\text { low grade ONB, SCC); chemoresistant tumor } \\
\text { (MM) }\end{array}$ & $35-45 \%$ & Mandatory & $\begin{array}{l}\text { Highly selected cases (according to the } \\
\text { grade of orbital invasion) }\end{array}$ \\
\hline $\begin{array}{l}\text { High grade cancer (SNUC, SCC-G3, NEC, } \\
\text { ONB grade IV, p53wt ITAC) }\end{array}$ & $50-80 \%$ & Mandatory & $\begin{array}{l}\text { Selected case (according to the response to } \\
\text { induction chemotherapy) }\end{array}$ \\
\hline
\end{tabular}

IP: inverted papilloma; FOLs: fibro-osseus lesions; JNA: juvenile nasopharyngeal angiofibroma; ACC: adenoid cystic carcinoma; ONB: olfactory neuroblastoma; SCC: squamous cell carcinoma; MM: mucosal melanoma; SNUC: sinonasal undifferentiated carcinoma; NEC: neuroendocrine carcinoma, p53wt ITAC, p53 wild type intestinal type adenocarcinoma.

Epiphora can result from stenosis of the nasolacrimal duct, lid malposition, or dry eye. Andersen et al. reported epiphora in $36 \%$ of cases ${ }^{47}$ while Imola et Schramm found a decreased epiphora rate of $13 \%$ using a prophylactic stenting of the nasolacrimal duct ${ }^{41}$.

\section{Conclusions}

Sinonasal benign and malignant tumors invading the orbit are rare and difficult to manage pathologies. An appropriate radiologic workup is paramount to assess the grade of orbital invasion and a thorough discussion with an expert radiologist can help in better defining it. To obtain complete excision of the tumor while reducing surgical morbidity and maximizing orbital preservation rates, an effective cooperation between otorhinolaryngologist, neurosurgeon, maxillofacial surgeon, and ophthalmologist is recommended, in order to select the best surgical strategy for each patient in a multidisciplinary perspective, as summarized in Table IV. In addition, based on the biology of the sinonasal tumor to treat, medical and radiation oncologists should be consulted in order to attempt multimodal therapies, including different schemes of induction chemotherapy and specific protocols of adjuvant chemoradiation. Contemporary studies show that invasion of the orbital apex is associated with reduced possibilities of complete tumor excision in both benign and malignant sinonasal tumors and adversely affects survival outcomes in case of cancers. Orbital preservation should be attempted, whenever feasible, and the reconstructive needs should be anticipated and addressed at the time of surgery so as to optimize functional and aesthetic outcomes of the preserved eye.

\section{References}

1 Ketcham AS, Wilkins RH, Vanburen JM, et al. A combined intracranial facial approach to the paranasal sinuses. Am J Surg 1963;106:698703. https://doi.org/10.1016/0002-9610(63)90387-8
2 Lisan Q, Kolb F, Temam S, Tao Y, et al. Management of orbital invasion in sinonasal malignancies. Head Neck 2016;38:1650-1606. https://doi.org/10.1002/hed.24490

3 Turri-Zanoni M, Lambertoni A, Margherini S, et al. Multidisciplinary treatment algorithm for the management of sinonasal cancers with orbital invasion: A retrospective study. Head Neck 2019;41:2777-2788. https://doi.org/10.1002/hed.25759

4 Carrau RL, Segas J, Nuss DW, et al. Squamous cell carcinoma of the sinonasal tract invading the orbit. Laryngoscope 1999;109:230-235. https://doi.org/10.1097/00005537-199902000-00012

5 Farina D, Borghesi A, Botturi E, et al. Treatment monitoring of paranasal sinus tumors by magnetic resonance imaging. Cancer Imaging 2010;10:183-193. https://doi.org/10.1102/1470-7330.2010.0025

6 Jørgensen M, Heegaard S. A review of nasal, paranasal, and skull base tumors invading the orbit. Surv Ophthalmol 2018;63:389-405. https:// doi.org/10.1016/j.survophthal.2017.07.001

7 Duan C, Dai Q, Liu Q, et al. Characteristics of sinonasal fibrous dysplasia: experience from a single department. Acta Otolaryngol 2018;138:50-55. https://doi.org/10.1080/00016489.2017.1367101

8 Georgalas C, Goudakos J, Fokkens WJ. Osteoma of the skull base and sinuses. Otolaryngol Clin North Am 2011;44:875-890, vii. https://doi. org/10.1016/j.otc.2011.06.008

9 Wang H, Sun X, Liu Q, et al. Endoscopic resection of sinonasal ossifying fibroma: 31 cases report at an institution. Eur Arch Otorhinolaryngol 2014;271:2975-2982. https://doi.org/10.1007/s00405014-2972-z

10 Ricalde P, Magliocca KR, Lee JS. Craniofacial fibrous dysplasia. Oral Maxillofac Surg Clin North Am 2012;24:427-441. https://doi. org/10.1016/j.coms.2012.05.004

11 Ye P, Huang Q, Zhou B. Endoscopic resection of ossifying fibroma involving paranasal sinuses and the skull base in a series of 15 cases. Acta Otolaryngol 2017;137:786-790. https://doi.org/10.1080/000164 89.2017.1278791

12 Turri-Zanoni M, Dallan I, Terranova P, et al. Frontoethmoidal and intraorbital osteomas: exploring the limits of the endoscopic approach. Arch Otolaryngol Head Neck Sur 2012;138:498-504. https://doi. org/10.1001/archoto.2012.644

13 Karligkiotis A, Appiani MC, Verillaud B, et al. How to prevent diplopia in endoscopic transnasal resection of tumors involving the medial orbital wall. Laryngoscope 2014;124:2017-2020. https://doi. org/10.1002/lary.24657

14 Leong LT, Ming BJ. Craniofacial fibrous dysplasia involving the orbit: a case report and literature review. Asia Pac J Ophthalmol (Phila) 2015;4:151-154. https://doi.org/10.1097/APO.0000000000000043

15 Elner VM, Burnstine MA, Goodman ML, et al. Inverted papillomas 
that invade the orbit. Arch Ophthalmol 1995;113:1178-1183. https:// doi.org/10.1001/archopht.1995.01100090104030

16 Wang J, Ford J, Esmaeli B, et al. Inverted papilloma of the orbit and nasolacrimal system. Ophthalmic Plast Reconstr Surg 2021;37:161167. https://doi.org/10.1097/IOP.0000000000001719

17 Johnson LN, Krohel GB, Yeon EB, et al. Sinus tumors invading the orbit. Ophthalmology 1984;91:209-217. https://doi.org/10.1016/ s0161-6420(84)34300-7

18 Saldana M, Wearne M, Beigi B, et al. Inverted papillomas of the nasal and paranasal sinuses that involve the ocular/adnexal region. Orbit 2013;32:366-369. https://doi.org/10.3109/01676830.2013.833251

19 Chaudhry IA, Taiba K, Al-Sadhan Y, et al. Inverted papilloma invading the orbit through the nasolacrimal duct: a case report. Orbit 200524:135-139. https://doi.org/10.1080/01676830590926530

20 Bajaj MS, Pushker N. Inverted papilloma invading the orbit. Orbit 2002;21:155-159. https://doi.org/10.1076/orbi.21.2.155.7189

${ }_{21}$ Mendenhall WM, Hinerman RW, Malyapa RS, et al. Inverted papilloma of the nasal cavity and paranasal sinuses. Am J Clin Oncol 2007;30:560-563. https://doi.org/10.1097/COC.0b013e318064c711

22 Cruz AA, Atique JM, Melo-Filho FV, et al. Orbital involvement in juvenile nasopharyngeal angiofibroma: prevalence and treatment. Ophthalmic Plast Reconstr Surg 2004;20:296-300. https://doi. $\operatorname{org} 10.1097 / 01$. iop.0000132163.00869.44

${ }_{23} \mathrm{Xu} \mathrm{Y,} \mathrm{Lin} \mathrm{G,} \mathrm{Lin} \mathrm{C,} \mathrm{et} \mathrm{al.} \mathrm{Treatment} \mathrm{and} \mathrm{prognosis} \mathrm{of} \mathrm{nasopharyn-}$ geal angiofibroma involving the eye and optic nerve. J Laryngol Otol 2012;126:1108-1113. https://doi.org/10.1017/S0022215112001831

24 Trivedi M, Desai RJ, Potdar NA, et al. Vision loss due to central retinal artery occlusion following embolization in a case of a giant juvenile nasopharyngeal angiofibroma. J Craniofac Surg 2015;26:e451453. https://doi.org/10.1097/SCS.0000000000001936

25 López F, Triantafyllou A, Snyderman CH, et al. Nasal juvenile angiofibroma: Current perspectives with emphasis on management. Head Neck 2017;39:1033-1045. https://doi.org/10.1002/hed.24696

26 Langdon C, Herman P, Verillaud B, et al. Expanded endoscopic endonasal surgery for advanced stage juvenile angiofibromas: a retrospective multi-center study. Rhinology 2016;54:239-246. https://doi. org/10.4193/Rhin15.104

27 Reyes C, Bentley H, Gelves JA, et al. Recurrence rate after endoscopic vs. open approaches for juvenile nasopharyngeal angiofibroma: a meta-analysis. J Neurol Surg B Skull Base 2019;80:577-585. https:// doi.org/10.1055/s-0038-1676562

28 Castelnuovo P, Battaglia P, Bignami M, et al. Endoscopic transnasal resection of anterior skull base malignancy with a novel $3 \mathrm{D}$ endoscope and neuronavigation. Acta Otorhinolaryngol Ital 2012;32:189191.

29 Safi AF, Behn L, Rothamel D, et al. Therapy of sinonasal malignancies invading the orbit-orbital exenteration versus preservation of the orbit plus radiotherapy. J Craniomaxillofac Surg 2017;45:258-261. https://doi.org/10.1016/j.jcms.2016.11.013

30 Vartanian JG, Toledo RN, Bueno T, et al. Orbital exenteration for sinonasal malignancies: indications, rehabilitation and oncologic outcomes. Curr Opin Otolaryngol Head Neck Surg 2018;26:122-126. https://doi.org/10.1097/MOO.0000000000000441

31 Castelnuovo P, Turri-Zanoni M, Battaglia P, et al. Sinonasal malignancies of anterior skull base: histology-driven treatment strategies. Otolaryngol Clin North Am 2016;49:183-200. https://doi.org/10.1016/j. otc.2015.09.012

32 Turner JH, Reh DD. Incidence and survival in patients with sinonasal cancer: a historical analysis of population-based data. Head Neck 2012;34:877-885. https://doi.org/10.1002/hed.21830
33 Neel GS, Nagel TH, Hoxworth JM,et al. Management of orbital involvement in sinonasal and ventral skull base malignancies. Otolaryngol Clin North Am 2017;50:347-364. https://doi.org/10.1016/j. otc.2016.12.010

34 Muscatello L, Fortunato S, Seccia V, et al. The implications of orbital invasion in sinonasal tract malignancies. Orbit 2016;35:278-284. https://doi.org/10.1080/01676830.2016.1193532

35 Maroldi R, Farina D, Battaglia G, et al. MR of malignant nasosinusal neoplasms. Frequently asked questions. Eur J Radiol 1997;24:181190. https://doi.org/10.1016/s0720-048x(97)01183-2

36 McCary WS, Levine PA, Cantrell RW. Preservation of the eye in the treatment of sinonasal malignant neoplasms with orbital involvement. A confirmation of the original treatise. Arch Otolaryngol Head Neck Surg 1996;122:657-659. https://doi.org/10.1001/archotol.1996.01890180063015

37 Iannetti G, Valentini V, Rinna C, et al. Ethmoido-orbital tumors: our experience. J Craniofac Surg 2005;16:1085-1091. https://doi. org/10.1097/01.scs.0000164332.81428

38 Suárez C, Ferlito A, Lund VJ, et al. Management of the orbit in malignant sinonasal tumors. Head Neck 2008;30:242-250. https://doi. org/10.1002/hed.20736

39 Patel SG, Singh B, Polluri A, et al. Craniofacial surgery for malignant skull base tumors: report of an international collaborative study. Cancer 2003;98:1179-1187. https://doi.org/10.1002/cncr.11630

40 Howard DJ, Lund VJ, Wei WI. Craniofacial resection for tumors of the nasal cavity and paranasal sinuses: a 25 -year experience. Head Neck 2006;28:867-873. https://doi.org/10.1002/hed.20432

41 Imola MJ, Schramm VL Jr. Orbital preservation in surgical management of sinonasal malignancy. Laryngoscope 2002;112:1357-1365. https://doi.org/10.1097/00005537-200208000-00007

42 Nishino H, Ichimura K, Tanaka H, et al. Results of orbital preservation for advanced malignant maxillary sinus tumors. Laryngoscope 2003;113:1064-1069. https://doi.org/10.1097/00005537-20030600000028

43 Battaglia P, Turri-Zanoni M, De Bernardi F, et al. Septal flip flap for anterior skull base reconstruction after endoscopic resection of sinonasal cancers: preliminary outcomes. Acta Otorhinolaryngol Ital 2016;36:194-198. https://doi.org/10.14639/0392-100X-748

44 Castelnuovo P, Turri-Zanoni M, Battaglia P, et al. Endoscopic endonasal management of orbital pathologies. Neurosurg Clin $\mathrm{N}$ Am 2015;26:463-472. https://doi.org/10.1016/j.nec.2015.03.001

45 Cherubino M, Turri-Zanoni M, Battaglia P, et al. Chimeric anterolateral thigh free flap for reconstruction of complex cranio-orbito-facial defects after skull base cancers resection. J Craniomaxillofac Surg 2017;45:87-92. https://doi.org/10.1016/j.jcms.2016.10.017

46 Rajapurkar M, Thankappan K, Sampathirao LM, et al. Oncologic and functional outcome of the preserved eye in malignant sinonasal tumors. Head Neck 2013;35:1379-1384. https://doi.org/10.1002/ hed. 23137

47 Andersen PE, Kraus DH, Arbit E, et al. Management of the orbit during anterior fossa craniofacial resection. Arch Otolaryngol Head Neck Sur 1996;122:1305-1307. https://doi.org/10.1001/archotol.1996.01890240013004

48 Bertin H, Huon JF, Guillot P, et al. Fibrous dysplasia of the orbital region: series of 12 cases and review of the literature. J Fr Ophtalmol 2020;43:467-476. https://doi.org/10.1016/j.jfo.2019.10.012

49 Ganly I, Patel SG, Singh B, et al. Craniofacial resection for malignant paranasal sinus tumors: report of an International Collaborative Study. Head Neck 2005;27:575-584. https://doi.org/10.1002/hed.20165 